\title{
The economic impacts of wheelchair use: Evidence from Central Java, Indonesia
}

\author{
Agnes Bhakti Pratiwi ${ }^{1,2,{ }^{*}}$ Hermawati Setiyaningsih, ${ }^{2}$ Rizki Mahardya, ${ }^{2}$ Firdaus Hafidz, ${ }^{2,3}$ \\ Diah Ayu Puspandari ${ }^{2,3}$ \\ ${ }^{1}$ Department of Medical Education and Bioethics, Faculty of Medicine, Public Health, and Nursing, \\ Universitas Gadjah Mada, Yogyakarta, Indonesia \\ ${ }^{2}$ Centre for Health Financing Policy and Health Insurance Management, Faculty of Medicine, Universitas \\ Gadjah Mada, Yogyakarta, Indonesia \\ ${ }^{3}$ Department of Health Policy and Management, Faculty of Medicine, Public Health, and Nursing, \\ Universitas Gadjah Mada, Yogyakarta, Indonesia
}

\section{Submitted: 12 July 2019 Revised: 21 November 2019 Accepted: 29 November 2019}

\begin{abstract}
An estimated $10 \%$ of the global population has disabilities, and 1 out of 10 require wheelchairs. Although imperative, the provision of wheelchair services remains challenging, especially in low resource settings. Interacting barriers in availability of wheelchair services and healthcare access can negatively affect households of people with disabilities in productivity and obtaining income. The availability of wheelchair services can potentially lessen the related economic burden. However, to date there is limited evidence concerning the economic gain of the wheelchair users in Indonesia. This study aims to analyze the economic impact of using wheelchairs on households in rural Central Java Province, Indonesia. Economic gains of wheelchair users were measured using a cross-sectional survey in Central Java, Indonesia during 2017. The questionnaires consisted of three main sections, namely general information, socio-economic information before and after using adaptive wheelchair, and income and spending related information. A total of 60 adaptive wheelchair users and parent proxy completed the questionnaires. More than half (55\%) of the respondents were male, became impaired in 1998, and used an adaptive wheelchair starting in 2009. Medical conditions of the respondents related to need for a wheelchair are cerebral palsy (29\%), paraplegia (29\%), and polio (15.5\%). Three-fourths of the respondents were working in the informal sector. On average, there is a significant increase of Rp. 217,662 in monthly household income between before and after using a wheelchair. However, there was no significant difference in spending before and after using a wheelchair. Respondents feel that using a wheelchair is beneficial particularly in mobility and helping in their activities. Wheelchair use can increase the income of households with disability. Clients responded that there have been several aspects which need further support, including skills improvement, employment generation for people with disabilities, and adequate public transportation facilities.
\end{abstract}

KEYWORDS disability; economic impact; household income; Indonesia; wheelchair

\section{Introduction}

The World Health Organization (WHO) estimated around $10 \%$ of the global population has disabilities and $10 \%$ of this disabled population requires wheelchairs. ${ }^{1}$ In 2012, The National

Socioeconomics Survey (SUSENAS) found $2.45 \%$ of the Indonesia population has a disability in various aspects, while in Yogyakarta province, $3.89 \%$ of the population has some disability. ${ }^{2}$ The Convention on

\footnotetext{
*Corresponding author: Agnes Bhakti Pratiwi

Department of Medical Education and Bioethics, Faculty of Medicine, Public Health, and Nursing, Universitas Gadjah Mada,, Jl. Farmako, Sekip Utara, Yogyakarta 55281, Indonesia

E-mail: agnes.b.p@ugm.ac.id
} 
the Rights of Persons with Disabilities emphasizes the commitment of signatory countries to ensure personal mobility for persons with disabilities and enable their independence. ${ }^{3}$ Providing mobility aids, such as wheelchairs, would fulfill the commitment as well as support people with disabilities to engage in their daily activities and social activities. ${ }^{1,4,5}$

However, the provision of appropriate wheelchair and adequate wheelchair services remains challenging, especially in low resource setting. ${ }^{1,6,7}$ The WHO has established The Guideline on the Provision of Manual Wheelchairs in Less Resourced Settings to increase appropriate wheelchair provision and services which is known as the 8-Step approach. ${ }^{1,8,9}$ Wheelchair provision is defined as the supply of wheelchair intervention to a disabled person by any private, state or Not for Profit Organization (NFPO) which provides services supplying wheelchairs based upon assessment of mobility needs by a professional. ${ }^{10}$

Wheelchair services are provisioned according to the needs and related medical condition of the wheelchair user. A study in West Bengal, India in 2005 showed a lack of appropriate wheelchair provision causing wheelchair abandonment by the recipients due to pain, fatigue, discomfort and lack of habitat ability. ${ }^{4,11}$ Evidently, the provision of wheelchairs according to the WHO 8-Step in Indonesia improved satisfaction with mobility significantly for children with proxies and adults with proxies. $^{8}$

Although studies on impact of wheelchair provision on quality of life and satisfaction on wheelchair use have been conducted in Indonesia, ${ }^{8}$ to our knowledge, studies on the economic benefits of wheelchair in Indonesia have not been conducted. This study aimed to investigate the economic benefits of providing wheelchair services for people with disabilities in Central Java. In particular, this study examined changes in productivity of wheelchair users and careers of people with disabilities in terms of income, household expenses, and the number of days absent from work. The results of this study will be beneficial to inform stakeholders whether wheelchair use can impact on households' economy.

\section{Methods}

A cross-sectional survey on economic impact was conducted among wheelchair users who attended a wheelchair service provision organized by UCPRUK (United Cerebral Palsy - Roda Untuk Kemanusiaan) and the Bureau of Social Services in the peri-urban near Yogyakarta, which included Magelang and Klaten between October-November 2017. Samples were purposively selected, and questionnaires were administered to adaptive wheelchair users or parent proxy who attended the event. To avoid mistakes and misunderstanding in filling the questionnaires, trained enumerators were present to assist respondents in administering the informed consent forms and answering questions related to the questionnaires. Respectively, 22 and 38 respondents in Magelang and Klaten participated in the survey. Participants were wheelchair users within the Social Service and UCPRUK network. Inclusion criteria were age more than 17 years old or parent proxy and adaptive wheelchair users for at least 6 months to capture their experience in using the wheelchair. Parent proxies answered the questionnaires for wheelchair users aged less than 17 years old. Exclusion criteria were people on temporary wheelchair.

The questionnaire on economic gain related to the use of adaptive wheelchairs consists of four parts; namely general information about patients, including gender, age, ethnicity, education, insurance status, and the type of adaptive wheelchairs used by patients; socio-economic information before and after using adaptive wheelchairs, including work, breadwinner in the family, the presence of assistants in engaging in daily activities, and caregivers; information regarding income and expenditure, including whether the use of adaptive wheelchairs affects household income and expenditure, food, use of health services, wheelchair repairs, and transportation; and qualitative questions whether adaptive wheelchairs affect income and expenditure in households. The data collected during the survey was entered by 
enumerator, operator, and member checks were performed for data validation. Any abnormalities were checked against the original documents. Data were analyzed using software Stata 13.0. Due to the presence of extreme values in the expenditure data, results were reported using means. The T-test was used to assess differences between the means or medians for household expenditure and income between before and after using adaptive wheelchair.

\section{Results}

\subsection{Respondents' characteristics}

A total of 60 adaptive wheelchair users and parent proxies from Klaten and Magelang completed the questionnaires. Adaptive wheelchair users of interest are those who use either children's wheelchair, rough rider, active, supportive, reclining, or standard adaptive wheelchair. The majority of respondents were standard and children adaptive wheelchair users, with a percentage of $43 \%$ and $39 \%$, respectively (Table 1 ). Not all respondents completed the survey questions. Reasons to leave blank some of the questions were due to difficulties to recall in answering some of the questions and choosing to not answering rather than giving answers that might be inaccurate. Around $88-100 \%$ of respondents answered each of the question.

Demographic characteristics of the wheelchair users include ages between 9 and 73 years with a mean of 31 years old (Table 1). More than half
(55\%) respondents were male, became impaired in 1998, and used an adaptive wheelchair starting year 2009. Medical conditions of the respondents related to need for a wheelchair are mainly cerebral palsy $(29 \%)$, paraplegia (29\%), and polio (15.5\%). On average, wheelchairs users who participated in this study live in a household with four other family members. Among the respondents 53\% and $47 \%$ were wheelchair users and parent proxy, respectively. Around $90 \%$ of respondents are covered by some health insurance and $80 \%$ are covered by the National Health Insurance or Jaminan Kesehatan Nasional (JKN). Education level for the majority of respondents was high school graduates (48\%), elementary school (25\%), and bachelor's degree (5\%), whereas the rest (22\%) have no formal education. Three-fourths of the respondents were working as entrepreneurs (informal sector), whereas a small proportion work as private employees (8\%), and the remaining are housewives, civil servants, retired, pastors, or unemployed.

\subsection{Economic gain of wheelchair users}

Household income was asked from the respondents according to how much the household earns in one month. Fifty-five out of sixty patients completed the questions on economic gain of wheelchair users. Table 2 shows that on average there was a significant increase of Rp. 217,662 in household income before and after using a wheelchair ( $p$-value

Table 1. Wheelchair users' characteristics

\begin{tabular}{|c|c|c|c|c|c|}
\hline Characteristics & $\mathbf{n}$ & Mean & SD & Min & Max \\
\hline Wheelchair user age (years) & 60 & 31.4 & 17.4 & 9 & 73 \\
\hline Number of family member & 60 & 4.1 & 1.5 & 1 & 8 \\
\hline Onset of disability (years) & 56 & 1998 & 10.2 & 1972 & 2011 \\
\hline Year of receiving wheelchair & 57 & 2009 & 8.1 & 1973 & 2017 \\
\hline $\begin{array}{l}\text { Duration time between onset of disability } \\
\text { and year of receiving wheelchair (years) }\end{array}$ & 53 & 10.5 & 9.8 & 0 & 36 \\
\hline $\begin{array}{l}\text { Time period using adaptive wheelchair } \\
\text { (years) }\end{array}$ & 57 & 7.9 & 8.1 & 0 & 44 \\
\hline
\end{tabular}

SD: standard deviation; min: minimum; max: maximum; $\mathrm{n}$ : number of participants answered the questions. 
Table 2. Household income wheelchair users

\begin{tabular}{|c|c|c|c|c|c|c|c|}
\hline \multirow{2}{*}{ Income } & \multicolumn{3}{|c|}{ Before using adaptive wheelchair } & \multicolumn{4}{|c|}{ After using adaptive wheelchair } \\
\hline & $\mathbf{n}$ & Mean & $\mathrm{Cl}$ & $\mathbf{n}$ & mean & $\mathbf{C l}$ & $p$-value \\
\hline $\begin{array}{l}\text { Total household } \\
\text { income (Rupiah) }\end{array}$ & 55 & 914,509 & $762,237-1,066,781$ & 55 & $1,132,171$ & $942,139-1,322,202$ & $0.001 * *$ \\
\hline $\begin{array}{l}\text { Total per capita } \\
\text { income (Rupiah) }\end{array}$ & 55 & 254,827 & $201,592-308,062$ & 55 & 311,037 & $248,373-373,701$ & $0.0018^{* * *}$ \\
\hline
\end{tabular}

Table 3. Household expenditure

\begin{tabular}{llllllll}
\hline \multirow{2}{*}{ Spending } & \multicolumn{6}{c}{ Before using adaptive wheelchair } & \multicolumn{5}{c}{ After using adaptive wheelchair } \\
\cline { 2 - 9 } & $\mathbf{n}$ & Mean & $\mathbf{C l}$ & $\mathbf{n}$ & Mean & $\mathbf{C l}$ & $p$-value \\
\hline Household (Rupiah) & 58 & $1,025,528$ & $845,655-1,205,400$ & 58 & $1,067,745$ & $871,285-1,264,204$ & 0.205 \\
\hline Cl: confidence interval & & & & & &
\end{tabular}

Table 4. Days absent from work

\begin{tabular}{lllllll}
\hline \multicolumn{2}{l}{ Before using adaptive wheelchair (day) } & \multicolumn{4}{l}{ After using adaptive wheelchair (day) } & $\boldsymbol{p}$-value \\
\hline $\mathbf{n}$ & Mean & $\mathbf{C l}$ & $\mathbf{n}$ & Mean & $\mathbf{C l}$ & 0.0875 \\
\hline 11 & 6.8 & $-1.1-14.7$ & 11 & 1.5 & $-0,4-3.3$ & \\
\hline
\end{tabular}

$\mathrm{Cl}$ : confidence interval

$=0.001)$. Per capita income before and after using adaptive wheelchair showed a significant increase of $\operatorname{Rp~56,209~(~} p$-value $=0.002$ ). While, there was showed no significant differences on household expenditure before and after using adaptive wheelchair.

Table 3 shows that $p$-value was 0.205 ( $p<$ $0.05)$. The $p$-value, obtained by performing $T$-test, implied that there was no significant difference in household expenditure between 6 months before using an adaptive wheelchair and 6 months after using an adaptive wheelchair. Interviews were done in October 2017, while most of respondents have used a wheelchair since 2009.

Respondents were asked about days of absence from work in a month. As shown in Table 4, only 11 of 60 respondents responded since nearly $50 \%$ of them work independently in informal sector. People who work independently are generally challenged to count their working and absent days from work therefore they could not answer this particular question. Of the samples who responded to the question, $p$-value of 0.087 was obtained, which means that there was no significant difference in days of absence from work between 6 months before using an adaptive wheelchair and 6 months afterward. However, the result may not be representative due to the small number of samples.

\subsection{Qualitative questions' result}

The study participants had a variety of responses whether an adaptive wheelchair affects income of the households. Some respondents feel that wheelchair use impacted positively on the household income.

"I cannot do my activities if there is no wheelchair." (Standard wheelchair user, 40 years)

Study participants who were wheelchair users felt that it would be difficult to perform their activities without using a wheelchair. Also, those who took the role as a breadwinner in the family could work more comfortably using a wheelchair. In addition, the wheelchair was beneficial in mobility from one place to another. 
"My child becomes much more independent, so I can look for a side job." (Caregiver, 46 years)

Respondents who were caregivers or parent proxies stated that they were able to go back to work full time and some for part-time work and were able to do work while taking care of their children.

Other respondents revealed that there was no difference in household income after using their wheelchair, but most participants expressed there is need for vocational training that may affect household income. The reason for this lack of change in income was that the wheelchair user was not the main person who earns money in the household.

Aside from affecting income, wheelchair use could also positively affect the spending of households. As moving becomes easier, wheelchair users can travel further and more often than previously without a wheelchair. Also using a wheelchair, it was easier for people with disabilities to engage in other activities outside their home. This empowerment trend indicates that wheelchair users become less dependent on caregivers or relatives to go from one place to another. In addition, their quality of life increased by having the opportunity to do other activities such as leisure and sightseeing outside their houses.

"Traveling becomes easier, my kid travels more often. She often goes out to buy snacks she likes; thus, my spending increases than before." (Caregiver, 46 years)

"Before using wheelchair I couldn't go for shopping, so I spend less." (Standard wheelchair user, 43 years)

There were several reasons why respondents report that wheelchair use does not affect household spending, such as, that it is the parents who took care of the disabled child, so that even with the use of wheelchair, there was no effect in household spending. Further, there was little or almost no maintenance cost for the wheelchair and if any, it is regarded as inexpensive.

\section{Discussion}

Monthly household income of most of the respondents (80\%) is less than $\mathrm{Rp} 1,500,000$ which is below the minimum wage (Yogyakarta province minimum wage is between $\mathrm{Rp} 1,454,200$ - $\operatorname{Rp~} 1,709,150)$. Around $18 \%$ of participants have a monthly income between $\mathrm{Rp} 1,500,000$

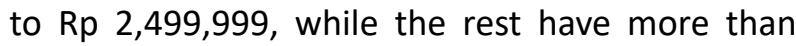
Rp $2,500,000$. This shows that the majority of respondents are middle to lower-income class. Since the majority of respondents are self-employed or informal workers, it may be difficult for them to remember days working and absent, which is possibly the reason not to answer this particular question. Among the respondents who answered, the result was $p$-value $0.087(p>0.05)$, and there was no significant difference in the number of days spent working between 6 months before using a wheelchair and 6 months after using a wheelchair. Maybe, this result is not representative of all respondents due to the small number of respondenlifets who answered this question.

Our study found that there was time gap with an average of 10.5 years from the first-time respondents become disabled and needing a wheelchair, with the year they actually received the wheelchair. On average, respondents received the wheelchair in year 2009. It indicates that unaffordability, unavailability or lack of wheelchair provision services in the past have hindered the respondents to receive the wheelchair they needed. ${ }^{12,13}$ Possible barriers to healthcare access were considerably greater for the people with disabilities. ${ }^{14}$ Thus, this can potentially hamper them to attain a better health outcome. ${ }^{15,16}$ In addition, without the appropriate wheelchair, mobility outside their homes becomes more difficult or not possible. This will lead to a poorer quality of lifepossibly related to lack of opportunities and access to social activities, education, and employment. Further, while wheelchair services are not within their reach, the downstream costs related to illness such as decubitus and deterioration in physical function, potentially increases household 
medical expenditures related to disability. ${ }^{17}$ Those interacting barriers are hypothetically affecting households with people with disabilities in the way that alters households' potential for obtaining income, spending time in employment, as well as household spending while allocating more proportion on health care use. Therefore, cumulatively, the availability of wheelchairs potentially lessens the related economic burdens.

In this study, income before and after using adaptive wheelchair showed a significant difference, with an increased income after using an adaptive wheelchair. According to one study conducted by Shore, ${ }^{18}$ there is an increased opportunity regarding employment of wheelchair users in Peru and Uganda, followed by an increase in income with time duration for follow-up observation of 30 months. However, the increase was not seen in Vietnam, which is possible because the data collection includes part-time employment and selfemployment. Anotherstudy on impact of wheelchair provision in Ethiopia, comparing wheelchair users and non-wheelchair users, revealed a 6.7 US dollar higher income per week among wheelchair users. ${ }^{19}$ However, household spending, and days absent from work showed no significant difference. The respondents' employment characteristics are mainly working as entrepreneur, which suggests that days of work can be flexible which is different from the nature of office work, where an employee is expected to be present at office during their working days. Household spending may affect households in terms of more spending on medicalrelated needs, repairs related to the wheelchair, or in terms of transportation costs. ${ }^{17}$ As public transportation facilities for people with disabilities are not adequate presently, people mainly travel with their own vehicles. For wheelchair users, it can mean limited access to transportation, which usually means a modified motorcycle to carry the wheelchair, or a car with modification becomes the main type of vehicles that can be used by wheelchair users. Nevertheless, with the barriers related to transportation, it is likely that even with the wheelchair use, it was not followed by an increase in transportation costs. Furthermore, for medical needs related to the disability condition, more than $80 \%$ of the respondents are covered by health insurance, which possibly covers most of their spending on health care, including the cost of wheelchair services.

According to the qualitative results from the respondents, we found that although not directly increasing the income of some households, wheelchair use increases a person's mobility inside and outside their house from one place to another, and participation in social activities. These findings are in line with the study that wheelchair use improved participation, integration, and independence. ${ }^{20,21}$ In contrast, another study revealed that with wheelchair use, there is relatively no change in the travel distance overtime for 30 months. An increased traveling distance was observed in the first year, however not until the end of the study period. ${ }^{18}$

One limitation of this study was that the interviews were conducted in October 2017, while the average respondents began using a wheelchair in 2009, which might cause some recall bias to occur. Another limitation related to time constraints was the short six months period after using wheelchair may not show significant change in household income. Further studies need to be conducted with communities from more diverse socio-economic groups, and with different criteria for the year of starting wheelchair use to minimize the possibility of recall bias.

\section{Conclusion}

Wheelchair use can positively impact on household income for persons with disabilities in rural areas in Central Java. This finding is indicated by the increase in household income in the span of six months from before to after obtaining wheelchair service.

In addition, given the significant benefits of wheelchair service for empowering people with disabilities, policymakers need to consider the existence of a comprehensive supplying and 
financing structure to ensure the availability and accessibility of wheelchair services and to provide equal opportunities for persons with disabilities to get appropriate wheelchair services.

\section{Acknowledgement}

The authors would like to thank wheelchair users and parents of children using wheelchairs for their time and contribution in this study. Thank you United Cerebral Palsy Roda Untuk Kemanusiaan (UCPRUK) for funding this study and providing access to supporting data, and Pusat KPMAK (Kebijakan Pembiayaan dan Manajemen Asuransi Kesehatan - Centre for Health Financing Policy and Insurance Management) Faculty of Medicine, Public Health and Nursing, Universitas Gadjah Mada; especially Pak Muttaqien. The authors also thank Mr. Ghatot Kersoharjo, director of UCPRUK Indonesia; Ms. Perth Rosen, director of programs at UCP Wheels for Humanity; Mr. Erik Hookom, Faculty of Medicine, Public Health and Nursing, Universitas Gadjah Mada; and Pak Agus Priyanto, Balai Penyelenggara Jamkesos Yogyaarta Province $D I Y$ for discussion and input in this study.

\section{Conflict of interest}

There is no conflict of interest.

\section{References}

1. World Health Organization. Guidelines on the provision of manual wheelchairs in less resourced settings; 2008

2. UCPRUK-UCPWFH. Jaminan Kesehatan Khusus Penyandang Disabilitas; 2016.

3. United Nation. Convention on the Rights of Persons with Disabilities; 2016

4. Shields M. Use of wheelchairs and other mobility support devices. Health reports. 2004;15(3):37.

5. Furlong $M$, Connor JP. The measurement of disability-related stress in wheelchair users. Archives of physical medicine and rehabilitation. 2007;1;88(10):1260-7.
6. Visagie S, Scheffler E, Schneider M. Policy implementation in wheelchair service delivery in a rural South African setting. African Journal of Disability. 2013;2(1).

7. McSweeney E, Gowran RJ. Wheelchair service provision education and training in low and lower middle income countries: a scoping review. Disability and Rehabilitation: Assistive Technology. 2019; 2;14(1):33-45.

8. Toro ML, Eke C, Pearlman J. The impact of the World Health Organization 8-steps in wheelchair service provision in wheelchair users in a less resourced setting: A cohort study in Indonesia. BMC Health Services Research. 2015; 16(1):26.

9. Williams E, Hurwitz E, Obaga I, Onguti B, Rivera A, Sy TR, Kirby RL, Noon J, Tanuku D, Gichangi A, Bazant E. Perspectives of basic wheelchair users on improving their access to wheelchair services in Kenya and Philippines: a qualitative study. BMC international health and human rights. 2017;17(1):22.

10. Bray N, Noyes J, Edwards RT, Harris N. Wheelchair interventions, services and provision for disabled children: a mixed-method systematic review and conceptual framework. BMC health services research. 2014;14(1):309.

11. Mukherjee G, Samanta A. Wheelchair charity: A useless benevolence in community-based rehabilitation. Disability and rehabilitation. 2005;27(10):591-6.

12. Hunt PC, Boninger ML, Cooper RA, Zafonte RD, Fitzgerald SG, Schmeler MR. Demographic and socioeconomic factors associated with disparity in wheelchair customizability among people with traumatic spinal cord injury. Archives of Physical Medicine and Rehabilitation. 2004;85(11):1859-64.

13. Borg J, Östergren PO. Users' perspectives on the provision of assistive technologies in Bangladesh: awareness, providers, costs and barriers. Disability and Rehabilitation: Assistive Technology. 2015;10(4):301-8.

14. Stillman MD, Bertocci G, Smalley C, Williams S, Frost KL. Healthcare utilization and associated 
barriers experienced by wheelchair users: A pilot study. Disability and health journal. 2017;10(4):502-8.

15. Sanchez J, Byfield G, Brown TT, LaFavor K, Murphy D, Laud P. Perceived accessibility versus actual physical accessibility of healthcare facilities. Rehabilitation Nursing. 2000;25(1):69.

16. Vergunst R, Swartz L, Mji G, MacLachlan M, Mannan H. 'You must carry your wheelchair'barriers to accessing healthcare in a South African rural area. Global health action. 2015;8(1):29003.

17. World Health Organization. WHO global disability action plan 2014-2021: Better health for all people with disability. World Health Organization; 2015.

18. Shore S. The long-term impact of wheelchair delivery on the lives of people with disabilities in three countries of the world. African Journal of Disability (Online). 2017;6:1-8.

19. Grider J, Wydick B. Wheels of fortune: The economic impacts of wheelchair provision in Ethiopia. Journal of Development Effectiveness. 2016;8(1):44-66

20. Kusumastuti P, Pradanasari R, Ratnawati A. The problems of people with disability in indonesia and what is being learned from the world report on disability. American journal of physical medicine \& rehabilitation. 2014;93(1):S63-7

21. Visagie $S$, Mlambo T, Van der Veen J, Nhunzvi C, Tigere D, Scheffler E. Impact of structured wheelchair services on satisfaction and function of wheelchair users in Zimbabwe. African Journal of Disability. 2016;5(1). 